73rd Conference of the Italian Thermal Machines Engineering Association (ATI 2018), 12-14 September 2018, Pisa, Italy

\title{
Influence of piston shape and injector geometry on combustion and emission characteristics of syngas in direct-injection spark-ignition engine
}

\author{
Matilde Fiore $^{a *}$, Annarita Viggiano ${ }^{\mathrm{a}}$, Emanuele Fanelli ${ }^{\mathrm{b}}$, \\ Giacobbe Braccio $^{\mathrm{b}}$, Vinicio Magi ${ }^{\mathrm{a}}$ \\ ${ }^{a}$ School of Engineering, University of Basilicata, Potenza 85100, Italy \\ ${ }^{b}$ Italian National Agency for New Technologies, Energy and Sustainable Economic Development (ENEA), Rotondella 75026, Italy
}

\begin{abstract}
This paper presents a numerical study of the influence of piston shape and injector geometry on combustion and emissions characteristics of a direct-injection spark-ignition engine fueled by syngas $(50 \%$ by volume of hydrogen, $50 \%$ by volume of carbon monoxide) under low/medium load conditions. Three different piston cup geometries namely: High-clearance Combustion Cup (HCC), Low-clearance Combustion Cup (LCC) and Omega Combustion Cup (OCC) have been considered with a compression ratio of 14. An axial full-cone gas jet injector has been considered together with a hollow-cone gas jet injector with several included half-angles, i.e. $30^{\circ}, 45^{\circ}, 52.5^{\circ}$ and $60^{\circ}$. Computational fluid dynamics modelling has been performed to simulate the combustion process. The results indicate that, in terms of performance, OCC shape is favorable, even if OCC generates relatively higher $\mathrm{NO}_{\mathrm{x}}$ than the other two configurations. A further analysis has been performed by simulating an engine with OCC piston shape and an included half-angle of injection of $30^{\circ}$, by varying the Start Of Injection (SOI). The results show that the flame propagation velocity reduces as the SOI advances, since the fuel distribution becomes more homogeneous approaching to a premixed case. However, the flame speed reduction is partially balanced by the disappearance of very lean regions thanks to fuel convection and diffusion.
\end{abstract}

(C) 2018 The Authors. Published by Elsevier Ltd.

This is an open access article under the CC BY-NC-ND license (https://creativecommons.org/licenses/by-nc-nd/4.0/)

Selection and peer-review under responsibility of the scientific committee of the 73rd Conference of the Italian Thermal Machines Engineering Association (ATI 2018).

Keywords: syngas; hydrogen; internal combustion engine; direct-injection; combustion; turbulence; emissions.

* Corresponding author. Tel.: 3400755758 .

E-mail address: matilde92@outlook.com . 


\section{Introduction}

Over the last few decades, the reduction of energy consumptions and pollutant emissions has led the research to investigate new fuelling strategies for internal combustion engines. The use of syngas in internal combustion engines is an intermediate step of the current transition from hydrocarbons-based to hydrogen-based fuels, and it could be a useful option to reduce consumptions and emissions. The use of syngas in carburated and port-injection engines has been investigated by several authors [1]-[5], who often experienced a decrease of volumetric efficiency due to the low air-excess-ratio and low fuel density. This brings to low output power for such engines. In order to solve this issue, the direct injection of syngas into the combustion chamber may be useful, since it decouples the fuel and air supply. Moreover, the fuel stratification would enable to operate with very lean mixtures as long as there is an adequate fuel concentration near the ignition system. The stratification would contribute to further extend the operating range by reducing the lower flammability limit of the overall mixture. In addition, the engine performance may be controlled by varying the amount of injected fuel without throttling, thus reducing the pumping cycle losses. Despite the advantages of fuel direct injection, in literature there are few works [6]-[8] dealing with the use of syngas in Direct Injection Spark-Ignition (DISI) engines. Indeed, few experiments regarding syngas direct injection are currently available at present to get a complete understanding of the physical phenomena. Moreover, engine optimization under syngas fuelling mode cannot be attained without a preliminary analysis to assess the influence of fluid dynamic and design parameters.

Computational Fluid Dynamics (CFD) is a useful tool in order to get reliable results by avoiding sophisticated testapparatus. In this work, a numerical model has been developed in ANSYS Fluent environment and simulates the compression-combustion-expansion cycle of a DISI engine fueled with syngas. Starting from a baseline case, with a High-clearance Combustion Cup (HCC) and an axial full-cone injector, piston shapes and injector included half-angles have been varied to characterize a discrete number of case studies.

The aim of this work is to provide new findings on the performance of DISI engines under syngas fuelling mode that may be helpful to assess the influence of the chamber geometry and injection angle. Such design parameters could play a significant role on charge stratification, thus affecting the overall combustion process. The numerical results of this work are a good starting point to optimize piston shape and injector geometry in order to achieve the maximum benefit from the use of syngas in this kind of engine.

\section{Mathematical model}

Reynolds-Averaged Navier-Stokes (RANS) equations for multidimensional, turbulent, reacting flows are solved together with the k- $\varepsilon$ turbulence model with Standard Wall Function (SWF) and a partially premixed combustion model that includes a reduced chemical kinetic mechanism for hydrogen-carbon monoxide combustion [9]. A $\mathrm{NO}_{x}$ sub-mechanism from the GRIMech 3.0 mechanism [10] has also been coupled to the kinetic mechanism. The Lewis number has been set equal to 1 for all species by neglecting the differential multi-component diffusion time. The partially premixed combustion model put together two approaches commonly used to handle turbulent premixed (Extended Coherent Flamelet Model) and diffusive (Steady Flamelet Model) flames, respectively. The Steady Flamelet approach reduces significantly the computational cost by solving the species and energy equations in terms of mixture fraction, $\mathrm{Z}$, which is a conserved scalar variable defined as:

$$
Z=\frac{n_{i}-n_{i, o x}}{n_{i, f}-n_{i, o x}}
$$

where $n_{i}$ is the elemental mass fraction of element $i$ and the subscripts $o x$ and $f$ denote the values at the oxidizer and fuel stream, respectively. The flamelet equations enables to reduce the number of transport equations which have to be solved in the model and, at the same time, to evaluate off-line the chemical contribution. The Extended Coherent Flamelet Model simulates the turbulent flame propagation by solving the transport equation of the progress variable, $c$, which measures the advancement of combustion based on the following definition: 

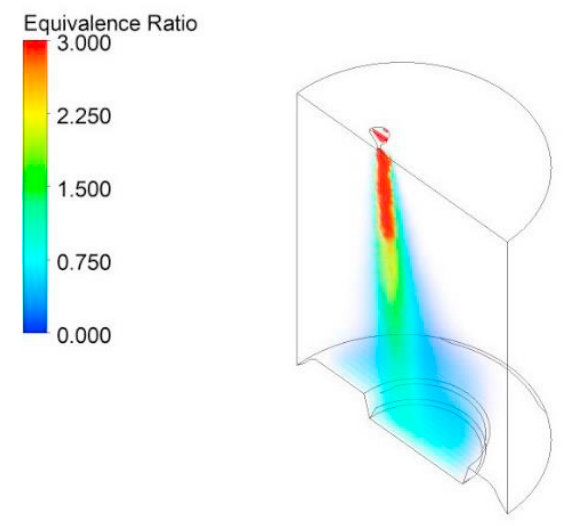

a)
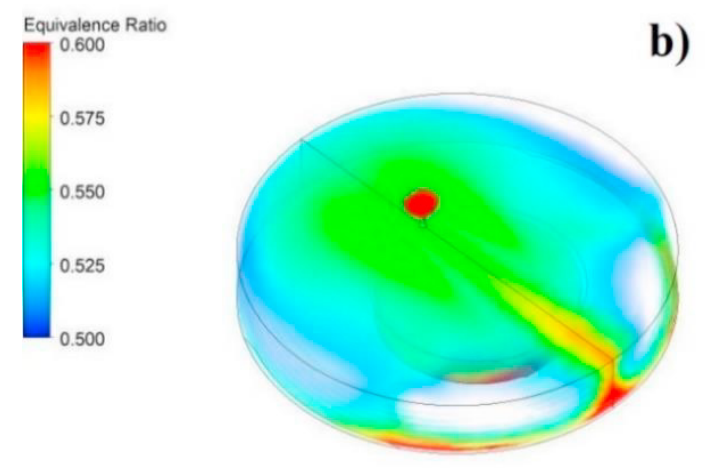

Fig. 1. Equivalence ratio contour plots at $170^{\circ} \mathrm{BTDC}$ (a) and $11^{\circ} \mathrm{BTDC}(\mathrm{b})$.

$$
c=\frac{\sum_{i} Y_{i}}{\sum_{i} Y_{i e q}}
$$

where $Y_{i}$ is the mass fraction of the $i$-th product species and the subscripts $e q$ stands for chemical equilibrium. The turbulence-combustion interaction is modelled by using a transport equation of the flame area density, $\sum$, which takes into account the corrugated and wrinkled flames developing at the combustion regimes typical of internal combustion engines. A spark ignition model has been implemented in order to simulate the heat release within the electrodes region by adding a source term in both $\sum$ and c equations to yield an ignition kernel with a radius equal to $3 \mathrm{~mm}$. The model assumes that the fuel within such zone is fully burned in a characteristic time of about $3^{\circ} \mathrm{CA}$.

\section{Model Validation}

The model has been validated by comparing the numerical results with the experimental data obtained by Hagos et al. [6]. The test case is a DISI engine with a compression ratio of 14 , running at $1500 \mathrm{rpm}$ and fueled by syngas $(50 \%$ by volume of $\mathrm{H} 2 ; 50 \%$ by volume of $\mathrm{CO}$ ), which is directly injected from $180^{\circ}$ to $100^{\circ} \mathrm{BTDC}$, in order to ensure an overall air-excess-ratio of 1.5. The Inlet Valve Closing (IVC) occurs at $48^{\circ} \mathrm{ABDC}$. The engine has a piston with an off-centered cup and an injector tilted at 15 degrees. Based on the engine geometry, the computations can be limited to half of the engine chamber. The simulation starts at $180^{\circ}$ BTDC by retaining the intake valve closed. An initial pressure of 0.822 bar and temperature of $300 \mathrm{~K}$ have been set to take into account the influence of the IVC. A mass fraction of $20 \%$ of residuals in chemical equilibrium have been included at the starting crank angle. The values of $k$

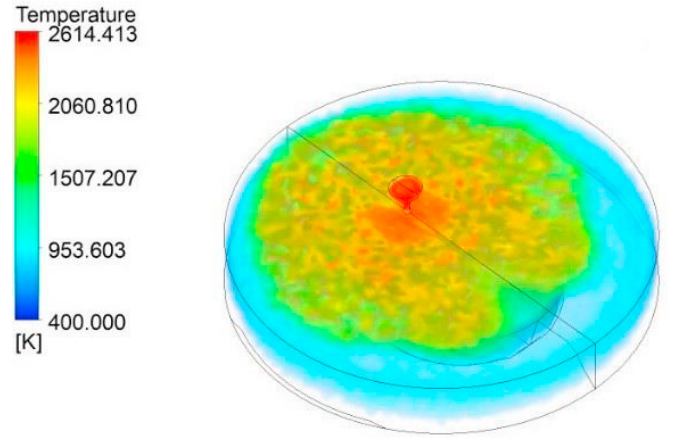

Fig. 2. Temperature distribution at $6^{\circ}$ ATDC

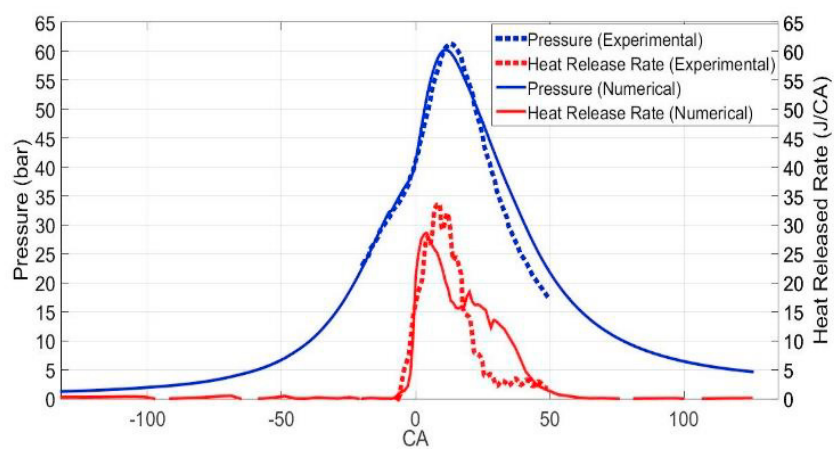

Fig. 3. Pressure and heat release rate vs CA. 
and $\varepsilon$ were computed by using Hayder et al. correlations [11], with an initial turbulent diffusivity of $70 \mathrm{~cm}^{2} / \mathrm{s}$. Cylinder walls and piston head are kept at a uniform temperature of $400 \mathrm{~K}$.

For the sake of simplicity, the intake process has not been taken into account in the simulations. Indeed, such a process slightly affects the fuel distribution for direct injection engines since the turbulent diffusivity quickly decays during the compression stroke. At TDC the turbulence intensity level asymptotically tends to an upper limit [11]. Thus, an accurate simulation of the intake stroke is considered unnecessary to study the combustion process near TDC. Figs. $1 \mathrm{a}$ and $1 \mathrm{~b}$ show the computed equivalence ratio distribution at $170^{\circ} \mathrm{BTDC}$ and at the spark timing $\left(11^{\circ} \mathrm{BTDC}\right)$ respectively, whereas Fig. 2 shows the temperature distribution during the combustion process at $6^{\circ}$ ATDC. A comparison between numerical and experimental results is presented in Fig. 3 in terms of pressure and heat release rate profiles. The agreement is excellent during the compression and the first part of combustion phase. The difference between the two profiles during the expansion stroke is probably due to other phenomena, i.e. heat transfer, crevices, blow-by, which are not investigated due to lack of experimental data.

\section{Results and discussion}

In order to reduce the computational cost, the simulations have been carried out by employing a simplified twodimensional axisymmetric chamber which has been discretized with a non-structured grid with about 20,000 cells. A grid sensitivity analysis has been previously performed for a simple pancake-chamber geometry [12], and the same resolution has been used for the final engine geometry.

The computations started at the inlet valve closing ( $48^{\circ}$ ATDC). An initial pressure of 1.1 bar and a temperature of $320 \mathrm{~K}$ are set. The initial turbulent diffusivity is $28 \mathrm{~cm}^{2} / \mathrm{s}$ from Hayder et al. [11]. Fuel injection lasts $80^{\circ} \mathrm{CA}$ starting from $90^{\circ} \mathrm{BTDC}$. The engine operates at lean conditions, with an overall air-excess-ratio of 2.15 in all the numerical tests. The wall temperature is kept constant and equal to $400 \mathrm{~K}$.

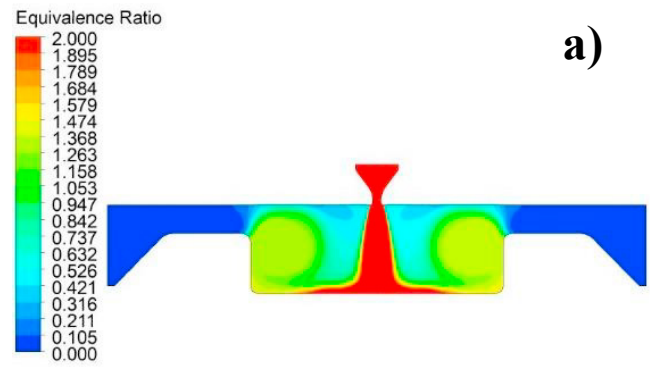

Equivalence Ratio

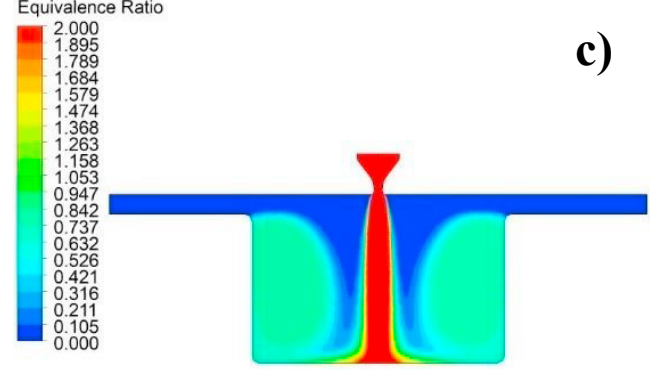

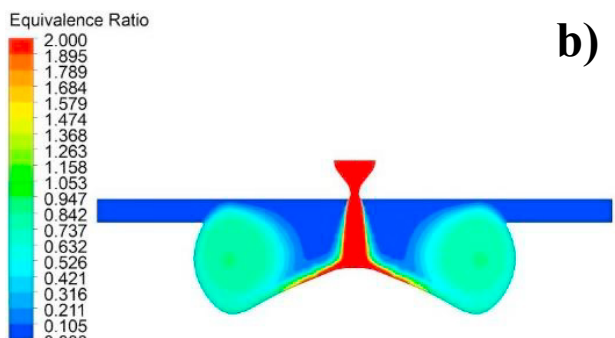

b)

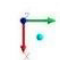

Fig. 4. Equivalence ratio contour plots at $10^{\circ}$ BTDC: (a) HCC; (b) OCC; (c) LCC 


\subsection{Influence of piston shape}

Three different piston shapes have been investigated with compression ratio of 14 . The first piston shape closely follows that of Hagos et al. [6], with the cup shifted towards the axis to obtain an axisymmetric chamber with the same clearance of $16 \mathrm{~mm}$ (High-clearance Combustion Cup - HCC)). Other two piston shapes are considered: a piston with an Omega Combustion Cup (OCC) and a piston with a reduced clearance and the same compression ratio (Lowclearance Combustion Cup - LCC). The spark plug is located along the axis at $5 \mathrm{~mm}$ from the piston head. Figs.4a-4c shows the equivalence ratio (ER) distributions at spark timing, i.e. $10^{\circ}$ BTDC. The interaction of the axial gas jet with the piston cup leads to different charge stratifications. The HCC engine leads to a distribution of ER ranging from 0.4 to 1.4 , whereas the OCC engine shows that the fuel is primarily concentrated into the main recirculation zone with ER ranging from 0.1 to 1.0. A large zone of recirculation is generated around the fuel jet with the LCC, where ER varies from 0 to 0.9. Pressure and heat release rate profiles vs CA for the three piston shapes are given in Figs. 5 and 6 , with an Omega Combustion Cup (OCC) and a piston with a reduced clearance and the same compression ratio (Lowclearance Combustion Cup - LCC). The spark plug is located along the axis at $5 \mathrm{~mm}$ from the piston head. Figs.4a-4c shows the equivalence ratio (ER) distributions at spark timing, i.e. $10^{\circ}$ BTDC. The interaction of the axial gas jet with the piston cup leads to different charge stratifications. The HCC engine leads to a distribution of ER ranging from 0.4 to 1.4 , whereas the OCC engine shows that the fuel is primarily concentrated into the main recirculation zone with ER ranging from 0.1 to 1.0. A large zone of recirculation is generated around the fuel jet with the LCC, where ER varies from 0 to 0.9 . Pressure and heat release rate profiles vs CA for the three piston shapes are given in Figs. 5 and 6 , respectively. The results show that a very rapid combustion takes place prior to TDC since ignition occurs immediately at the end of fuel injection. Fig. 6 shows that the burning timing is strongly affected by the piston shape and it tends to increase from HCC to LCC configuration. This is because the fuel tends to be confined in the cup as long as the clearance decreases.

Engine performances are given in Fig.7. The indicated work has been computed by the integral $\int p d V$ from IVC to EVO, the fuel mass burned is expressed as a percentage of the total injected fuel and the thermal efficiency is given as the ratio of the indicated work to the total heat released. The OCC engine shows the best performance due to a better fuel stratification.

Emissions of $\mathrm{NO}_{\mathrm{x}}$ and $\mathrm{CO}$ are given in Fig. 8 for the three cases, whereas $\mathrm{HC}$ emissions are negligible. As expected, $\mathrm{NO}_{\mathrm{x}}$ are related to in-cylinder temperature, which is higher in the OCC-case, while CO emission mainly depends on the fraction of unburned CO-fuel, which is higher in the HCC-case.

\subsection{Influence of included half-angle of injection}

The influence of the angle of fuel injection on the performance and emissions has been analysed for the OCC engine, for several included half-angles, i.e. $0^{\circ}, 30^{\circ}, 45^{\circ}, 52.5^{\circ}$ and $60^{\circ}$. Fig. $9 \mathrm{a}-\mathrm{b}$ shows equivalence ratio contour plots with $30^{\circ}$ and $60^{\circ}$ included half-angle of injection, respectively, whereas Fig.10a-b shows a comparison in terms of pressure and heat release rate profiles. The engine performance are depicted in Fig.11a, while Fig.11b shows

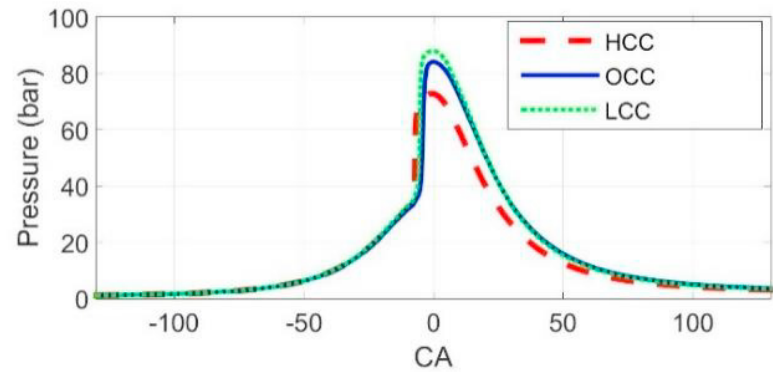

. Fig. 5. Pressure profiles vs CA for the three piston shapes

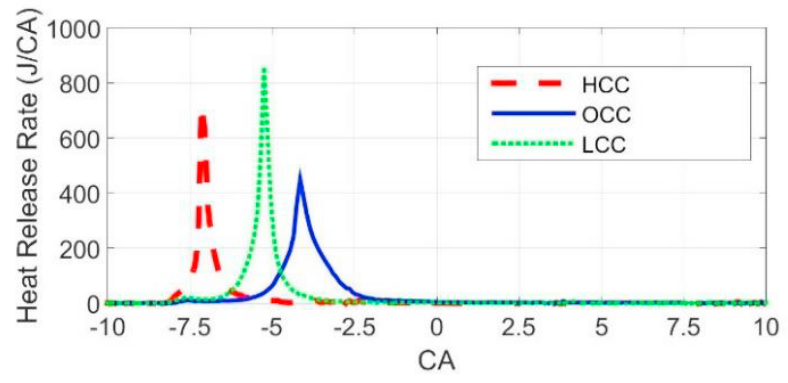

Fig. 6. Heat release rate profile vs CA for the three piston shapes. 
emissions of $\mathrm{NO}_{\mathrm{x}}$ and $\mathrm{CO}$ at the EVO. Fig. 11a shows that the thermal efficiency considerably decreases with an included half-angle equal to $60^{\circ}$. This is a consequence of a low-pressure region, located between the jet and the
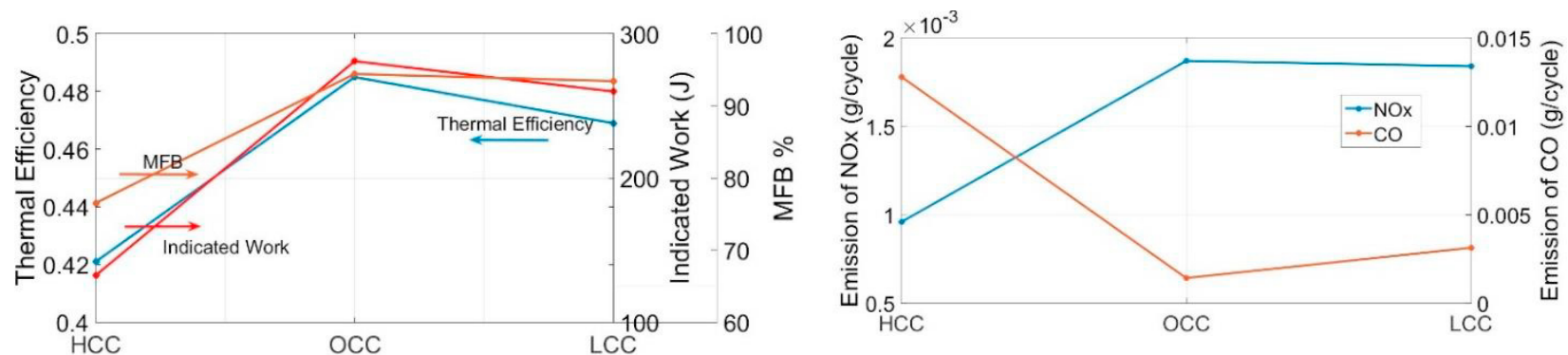

Fig. 7. Thermal Efficiency, Indicated Work and Mass of Fuel Burnt (MFB) for the three piston shapes.

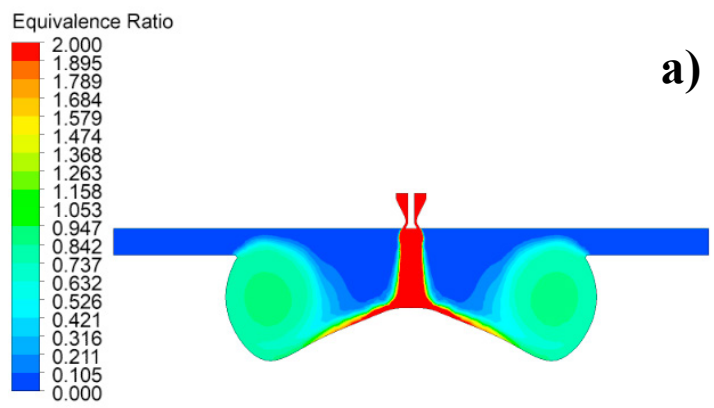

Fig. 8. Nitrogen oxides and carbon monoxide at the exhaust valve opening (EVO) for the three piston shapes.

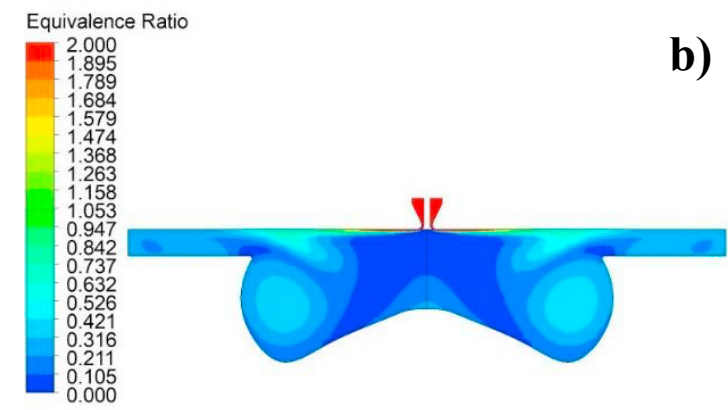

Fig. 9. Equivalence ratio contour plots at $10^{\circ}$ BTDC: (a) $30^{\circ}$ included half-angle of injection; (b) $60^{\circ}$ included half-angle of injection.
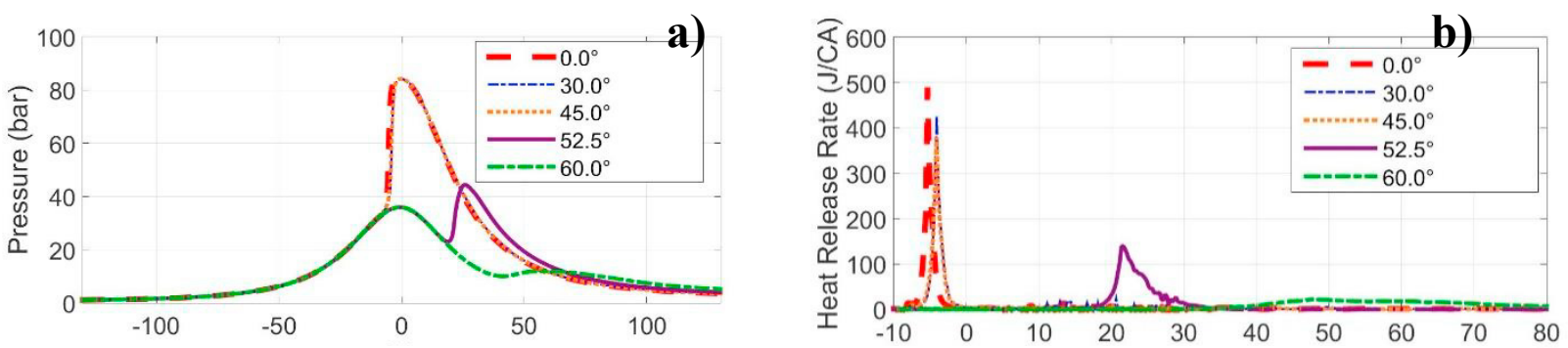

Fig. 10. In-cylinder pressure (a) and heat release rate (b) profiles as a function of CA for various included half-angles of injection
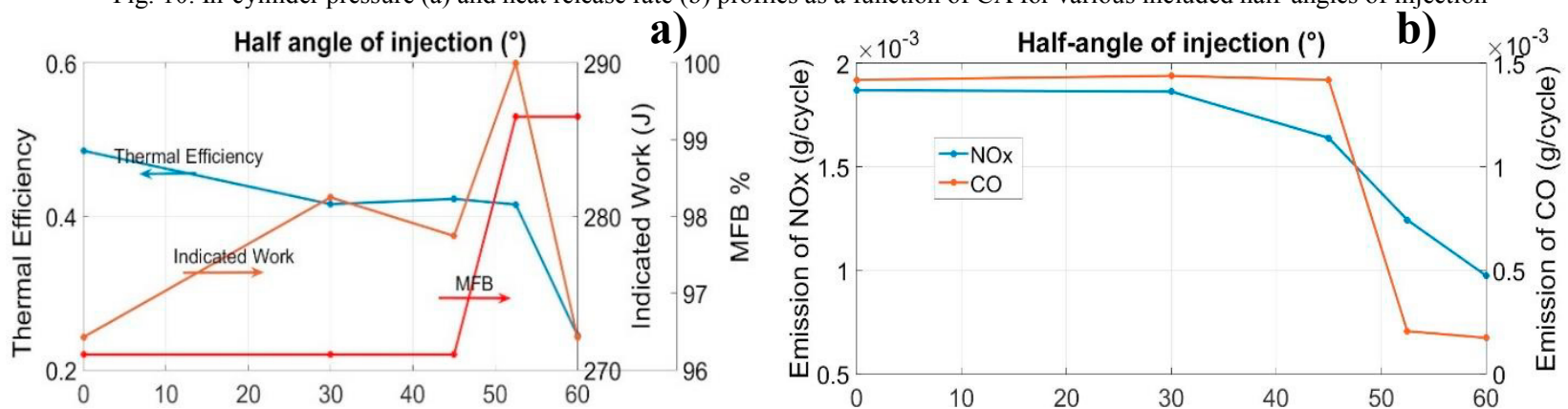

Fig. 11. Engine performance (a) and $\mathrm{CO}$ and $\mathrm{NO}_{\mathrm{x}}$ emissions (b) for various included half-angles of injection 
cylinder head, caused by the air entrainment that deflects the jet towards the cylinder head where it collapses (Fig. $9 b)$. This flow structure does not provide a good stratification within the combustion chamber.

\subsection{Influence of Start of Injection (SOI)}

An investigation has also been performed in order to evaluate the influence of start of injection on the stratification level. Two more SOI are considered, i.e. $110^{\circ}$ and $130^{\circ} \mathrm{BTDC}$, and the ER distributions at $10^{\circ} \mathrm{BTDC}$ are shown in

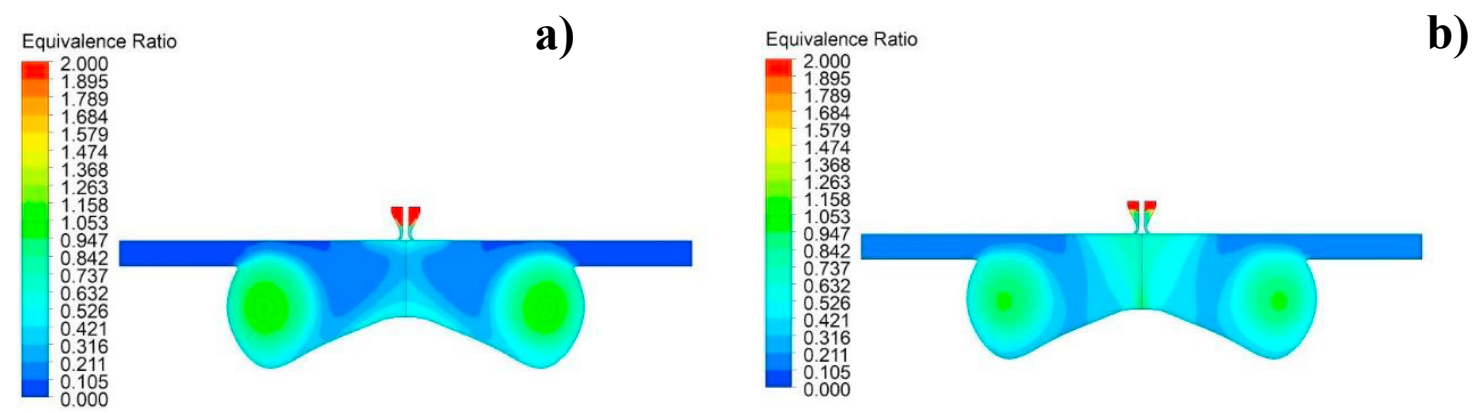

Fig. 12. Equivalence ratio contour plots at $10^{\circ} \mathrm{BTDC}$ : (a) SOI of $110^{\circ} \mathrm{BTDC}$; (b) SOI of $130^{\circ} \mathrm{BTDC}$.

Fig.12. The figure shows that a lower stratification is obtained advancing the fuel injection, i.e. $130^{\circ} \mathrm{BTDC}$. Indeed, by increasing the time interval between the end of injection and the start of ignition, there is more time for air-fuel mixing and a uniform distribution is gradually approached. Fig.13a-b shows the computed pressure and heat release rate profiles, respectively, whereas Fig. 14 and Fig. 15 show the engine performance and emissions for various SOI, respectively. The figures show that the best results are obtained with a SOI of $90^{\circ} \mathrm{BTDC}$. Indeed, under this operating condition, a good stratification is recovered that strongly influences the engine performance.

a)

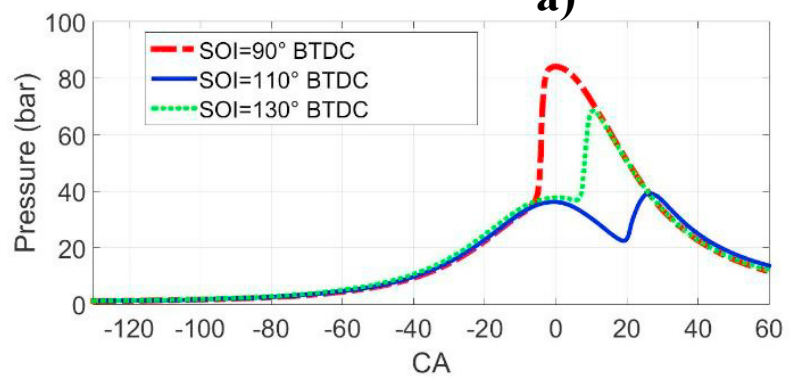

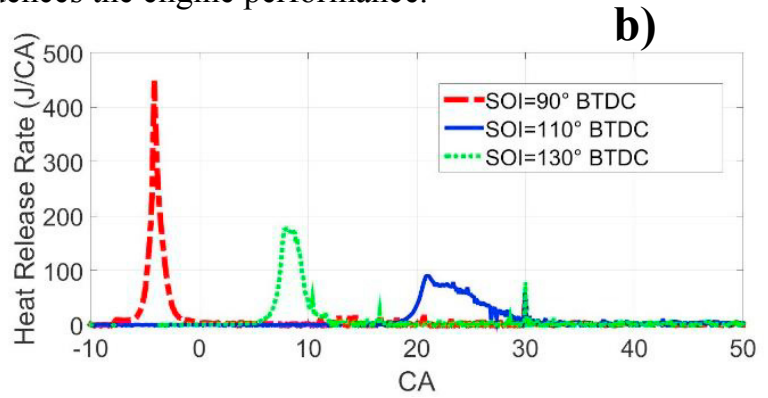

Fig. 13. Pressure (a) and heat release rate (b) profiles for various SOI.

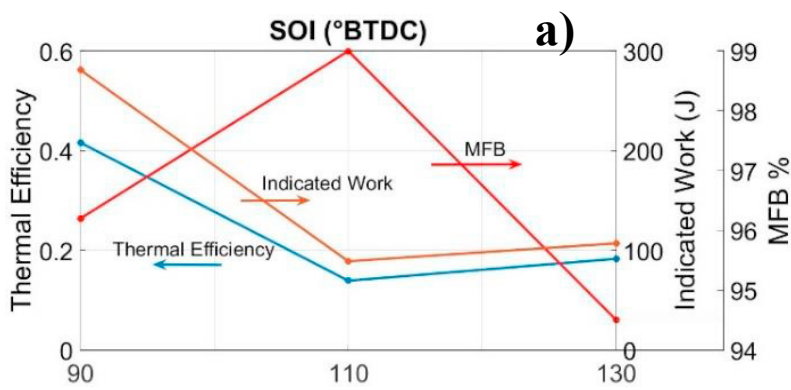

Fig. 14. Thermal Efficiency, Indicated Work and Mass of Fuel Burnt (MFB) for various SOI.

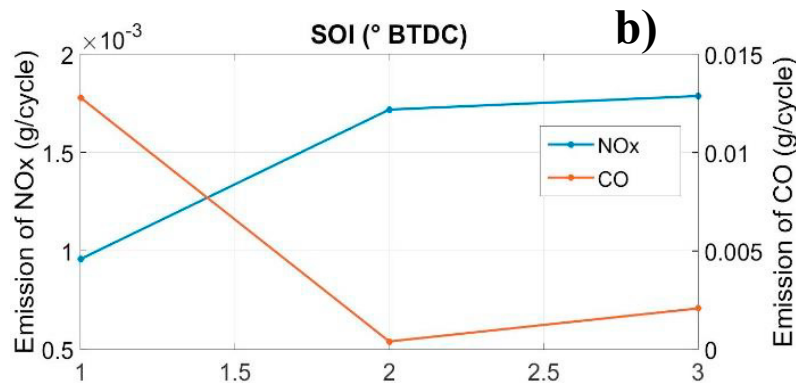

Fig. 15. Nitrogen oxides and carbon monoxide at the exhaust valve opening (EVO) for various SOI. 


\section{Conclusions}

In this work, CFD simulations have been carried out to analyze the impact of piston shape and injection specifications on the emissions and performance of a DISI engine fueled by syngas. Three different piston shapes are analyzed. The investigation clearly shows that the use of an OCC piston shape is certainly the best choice in order to optimize the combustion process and engine performance, even if this leads to higher $\mathrm{NO}_{\mathrm{x}}$ emissions. Several included half-angle fuel injections are also analyzed. The engine performances are influenced by the included half-angle of injection, on which the charge stratification strongly depends. For lower angles of injection $\left(0^{\circ}, 30^{\circ}, 45^{\circ}\right)$, a very rich mixture region along the cylinder axis leads to a slight reduction of the mass of fuel burnt. On the other hand, for higher angles of injection $\left(52.5^{\circ}, 60^{\circ}\right)$, a collapse of the gas jet on the cylinder head occurs, resulting unfavorable to ensure an efficient flame propagation.

Furthermore, an analysis has been performed for various SOI. An advanced fuel injection tends in general to decrease the engine performance since the engine operates at lean conditions with a low overall air-excess-ratio. Nevertheless, the lowest performance is achieved at intermediate conditions, i.e. $\mathrm{SOI}=110^{\circ} \mathrm{BTDC}$, since the fluid structure neither promotes the flame propagation towards rich regions, nor provides an adequate homogeneous mixture.

A limitation of this investigation is due to the spark plug location which is constrained along the axis due to the axisymmetric chamber. Based on the characteristics of the fuel stratification, the ER value along the cylinder axis is not optimal for ignition to occur, whereas the fuel is moved by convection towards the main recirculation region. It follows that the spark plug arrangement along the cylinder axis is not the best choice in order to guarantee good engine performance in a wide range of operating conditions. To this end, three-dimensional computations will be carried out in an incoming work to optimize the spark plug location in order to improve engine performance and reduce emissions.

\section{References}

[1] Sridhar, B. G., and Yarasu R. B. "Facts about producer gas engine." in Paths to Sustainable Energy, (2010), InTech.

[2] Gobbato, P., Masi, M., and Benedetti, M. "Performance Analysis of a Producer Gas-fuelled Heavy-duty SI Engine at Full-load Operation." 70 ${ }^{\text {th }}$ Conference of the Italian Thermal Machines Engineering Association, ATI 2015, (82) (2015): 149-155.

[3] Ji, C., and Wang, S., "Combustion and emissions performance of a hybrid hydrogen-gasoline engine at idle and lean conditions." International Journal of Hydrogen Energy, 1(35) (2010): 346-355.

[4] Hagos, F. Y., Aziz, A. R. A., Sulaiman, S. A., "Study of Syngas Combustion Parameters Effect on Internal Combustion Engine." Asian Journal of Scientific Research, (6) (2013): 187-196.

[5] Hagos, F. Y., Aziz, A. R. A., Sulaiman, S. A., "Trends of Syngas as a Fuel in Internal Combustion Engines" Advances in Mechanical Engineering, (2015).

[6] Hagos, F. Y., Aziz, A. R. A., Sulaiman, S. A., "Syngas (H2/CO) in a spark-ignition direct-injection engine. Part 1: Combustion, performance and emissions comparison with CNG", International Journal of Hydrogen Energy, 31(39) (2014): 17884-17895.

[7] Hagos, F. Y., Aziz, A. R. A., Sulaiman, S. A., "Effect of injection timing on combustion, performance and emissions of lean-burn syngas (H2/CO) in spark-ignition direct-injection engine", International Journal of Engine Research, 9(17) (2015): 921-933.

[8] Hagos, F. Y., Aziz, A. R. A., Sulaiman, S. A., "Methane enrichment of syngas (H2/CO) in a spark-ignition direct-injection engine: Combustion, performance and emissions comparison with syngas and Compressed Natural Gas", Energy, (90) (2015): 2006-2015.

[9] Kéromnès, A., Metcalfe, W. K., Heufer, K. A., Donohoe, N., Das, A. K., Sung, C. J., Herzler, J. , Naumann, C., Griebel, P., Mathieu, O., Krejci, M. C., Petersen, E. L., Pitz, W. J., Curran, H. J., “An Experimental and Detailed Chemical Kinetic Modelling Study of Hydrogen and Syngas Mixtures at Elevated Pressures", Combustion and Flame, (160) (2013): 995-1011.

[10] Smith, G. P., Golden, D. M., Frenklach, M., Moriarty, N. W., Eiteneer, B., Goldenberg, M., Bowman, C. T., Hanson, R. K., Song, S., Gardiner, W. C. Jr., Lissianski, V. V., Qin, Z.: http://www.me.berkeley.edu/gri_mech/

[11] Hayder, M., Varma A. and Bracco F., "A limit to TDC turbulent intensity in internal combustion engines", Journal of Propulsion and Power, 4(1) (1985): 300-308.

[12] Fiore M., "Sviluppo di modelli teorico-numerici per l'analisi di motori a combustione interna alimentati con gas di sintesi”, Master Thesis, School of Engineering, University of Basilicata, 2018. 